\title{
HYPOXIA AND REPRODUCTIVE HEALTH Hypoxia and labour
}

\author{
Susan Wray, Mona Alruwaili and Clodagh Prendergast \\ Department of Women's and Children's Health, University of Liverpool, Liverpool, Merseyside, UK \\ Correspondence should be addressed to SWray; Email: s.wray@liverpool.ac.uk
}

This paper forms part of a special section on Hypoxia and Reproductive Health. The guest editor for this section was Dr Jacqueline Maybin (University of Edinburgh, UK)

\begin{abstract}
Intermittent myometrial hypoxia is a normal feature of labour, as the powerful contractions compress blood vessels. In this review, we focus on the relation between hypoxia, myometrial metabolism, and contractility. We dissect how hypoxia can feedback and limit an ongoing contraction and help prevent foetal distress. The mechanisms involve acidification from lactate, decreased excitability, and a fall of intracellular calcium concentration. As this cycle of contraction and relaxation repeats in labour, the hypoxia also engenders mechanisms that increase force; hypoxia-induced force increase, HIFI. We also discuss the role of the myometrial blood vessels in dysfunctional labour, which is associated with lactic acidosis. In synthesising these studies, we have attempted to unify findings by considering the importance of experimental protocols and finding direct mechanistic evidence from human myometrium or in vivo studies. We have made suggestions for future studies to fill the holes in our understanding and speed up the translation of our knowledge to improve births for mothers and babies everywhere.

Reproduction (2021) 161 F67-F80
\end{abstract}

\section{Introduction}

\section{Background}

For millennia birth attendants would be aware of what were normal or abnormal patterns of maternal activity during labour. These might include tightening of the stretched abdomen due to contractions, changes in respiratory patterns, experience pain, and dilation of the birth canal. Without forceps until the 17 th century, pain relief in the 19th or access to safe Caesarean sections in the 20th century, it is not surprising that childbirth was feared and a significant cause of female and neonatal deaths. As these advances were made improving outcomes, attention shifted to the black box that was the uterus and its activity. Further technical advances enabled the monitoring of uterine contractions and foetal heart rate, and much greater survival of neonates born prematurely. Hypoxia, before or during labour, however, remains a significant challenge to clinical teams, from its origin, detection, prevention, and treatment. This review is addressing the first of these, its origin, and specifically the role of the myometrium in hypoxia. For over 60 years researchers have been studying the relation between uterine activity, perfusion, the course of labour and neonatal outcomes (references throughout). Here we introduce the key concepts, review, and synthesize data and suggest underlying, testable mechanisms for taking this crucial work further.

\section{Focus}

Labour presents several challenges to mother and fetus. The long-lasting physical and mental challenge has often been compared to a marathon and the effort required giving rise to its name, 'labour'. Physiologically and biochemically we understand that changes have occurred within the woman's reproductive tract ahead of labour starting. Most notably, these nearly always include softening and shortening of the cervix, Braxton Hicks contractions, the foetal head engaging with the cervix, and a biochemical preparedness for hypoxic conditions. At a molecular and hormonal level, the myometrium is being primed to produce strong, frequent, and coordinated contractions.

The focus of this review is hypoxia in labour. By this, we mean the effects of the normal and abnormal reductions of uterine blood flow that accompany contractions, and not any chronic pathology of the myometrium or its blood supply, nor the effects of living at high altitude. Myometrial hypoxia is a normal accompaniment to labour and indeed may play a role in strengthening uterine contractions. Hypoxia, if prolonged, however, will contribute to dysfunctional (slow to progress) labours. We are concerned with four major questions: (1) what is the evidence for hypoxia in the myometrium, (2) what is the functional effect of hypoxia on uterine contractility and labour, (3) what 
mechanisms underly these effects in the myometrium, and (4) what is the contribution of the myometrial vasculature. When possible, we have prioritised data obtained in women or human tissue, but much relevant information comes, of necessity, from studies in animal models, (species indicated if not rat or mouse).

\section{Structure}

To understand how uterine contractions, cause hypoxia, it is first necessary to consider the relative anatomy of the myometrium and its blood supply, and then myometrial physiology, specifically how uterine contractions in labour arise. Metabolism and function are closely linked in muscles and the myometrium is no exception. We, therefore, discuss the particular features of myometrial biochemistry and metabolism, including their shift to prepare for the hypoxic conditions which will occur in labour. This section of the review also brings in $\mathrm{pH}$ and its changes with contraction and hypoxia. We then discuss the critical evidence from in vivo and in vitro studies, made in animal models but also women, leading to the conclusion that uterine contractions occludebloodvessels. This causes hypoxia within the myometrium, reduces placental perfusion and can affect foetal oxygenation. The feedback of this hypoxia and acidification on the force of contractions are explained. The circumstances and mechanisms by which hypoxia may reduce or increase uterine contractions is explained. These findings have been translated to explain the physiological cause of dysfunctional labour, (slow to progress), labours, as lactate produced in hypoxic conditions, accumulates. Furthermore, we describe how lactate concentrations in amniotic fluid can be used to help predict the outcome of labour, and the trialling of oral bicarbonate to improve labour outcome in women labouring dysfunctionally. An area of much less certainty is the role of the uterine blood vessels in all these processes; how do they respond to repeated compressions and the need to fully relax between contractions. Is there a role for reactive hyperaemia for example? We finish by asking, is there a maternal phenotype that adds to the risk of the myometrium or its blood vessels, functioning poorly in labour. In the 21 st century, there are still mothers dying in labour or having to have unplanned surgical interventions to safely deliver their child, because we still do not understand hypoxia in labour - a call to arms is made for future work.

\section{Vasculature of the uterus}

\section{Anatomy}

The blood supply to the pregnant and non-pregnant human uterus is well described and the latter shown in Fig. 1. Briefly, the supply comes mainly from the uterine artery, but also the ovarian arteries. The vessels form an anastomosing network, interconnecting across the circumference of the uterus (Farrer-Brown et al.
1970). This potentially bi-directional supply ensures considerable redundancy and helps maintain uterine perfusion. Arcuate arteries branch off the uterine artery and run circumferentially in the outer third of the myometrium. Radial arteries branch out and traverse the myometrium inwardly towards the endometrium. At the myometrial/endometrial boundary, the radial arteries branch to form the basal and spiral arteries. The tortuous course of the vessels through the myometrium allows for the enlargement of the uterine cavity and the inevitable stretching of the vessels as pregnancy progresses. Endometrial capillaries drain into venules that converge to form larger collecting veins that radially traverse the inner myometrium, growing in size until they join the circumferentially running arcuate veins in the outer myometrium and finally drain into the uterine vein (Farrer-Brown et al. 1970). The remodelling that occurs in pregnancy is beyond the scope of this review and has been covered elsewhere (Pijnenborg et al. 2006, Osol \& Mandala 2009). Of note, however, uterine, arcuate, and radial arteries undergo outward remodelling and demonstrate reduced reactivity to vasoconstrictive agents, allowing a greater blood flow to the uterus, and the uterine veins increase in diameter and distensibility (Page et al. 2002).

\section{Physiology}

Vascular tone appears to be increased in myometrial arteries from pregnant women and animals compared to non-pregnant (Eckman et al. 2012, Xiao et al. 2013). An increase of intracellular $\mathrm{Ca}^{2+}$ concentration $\left(\left[\mathrm{Ca}^{2+}\right]_{\mathrm{i}}\right)$ is integral to determining tone in smooth muscle, as detailed in the next section, and see Fig. 2. An important negative-feedback loop exists in vascular smooth muscle. Calcium ion entry stimulates release of $\mathrm{Ca}^{2+}$ via ryanodine receptors on the sarcoplasmic

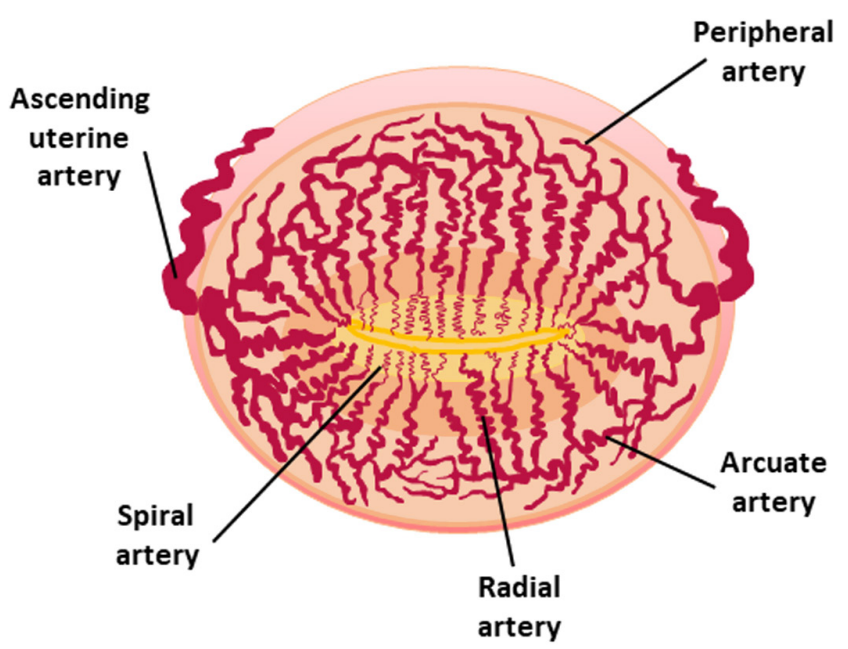

Figure 1 Transverse section through the non-pregnant human uterus showing the embedded arteries. Drawn by Dr Clodagh Prendergast. 
reticulum (SR) in the form of $\mathrm{Ca}^{2+}$ sparks, which activate large conductance $\mathrm{Ca}^{2+}$-activated $\mathrm{K}^{+}$channels $\left(\mathrm{BK}_{\mathrm{Ca}}\right)$. Opening of these channels produces a spontaneous transient outward $\mathrm{K}^{+}$current (STOC) that hyperpolarises the cell, thereby decreasing the opening of L-type, the voltage-operated $\mathrm{Ca}^{2+}$ channels (VOCC), and causing vasorelaxation (Jaggar et al. 1998). As part of the haemodynamic adaptation to pregnancy, there is an upregulation of $\mathrm{BK}_{\mathrm{Ca}}$ channels and increased $\mathrm{Ca}^{2+}$ spark frequency in uterine arteries (Rosenfeld et al. 2005, Hu et al. 2011, 2019), presumably attenuating tone and aiding the larger blood flow experienced in pregnancy. Chronic hypoxia can downregulate $\mathrm{BK}_{\mathrm{Ca}}$ channels in uterine arteries and lead to increased ovine vascular tone (Hu et al. 2012, Xiao et al. 2013).

The responsiveness of human term pregnant myometrial arteries has been well studied; vessels constrict in response to endothelin (ET-1), U46619, vasopressin, noradrenaline, angiotensin II. Of note, high concentrations of oxytocin can constrict myometrial vessels (Maigaard et al. 1986).
The endothelium also plays a vital role in the regulation of vascular tone by secreting several vasodilating (NO, $\mathrm{PGI}_{2}$, EDHF and $\mathrm{H}_{2} \mathrm{~S}$ ) and vasoconstricting (ET-1, EDCF) substances (Galley \& Webster 2004). The expression and activity of eNOS (endothelial nitric oxide synthetase), is increased in uterine artery in pregnancy (Nelson et al. 2000), but endothelial vasodilatory pathways are also altered in disease states, including pre-eclampsia (Vanhoutte et al. 2017).

\section{Physiology of myometrial contraction}

The mechanism of force production in the myometrium is like that in other smooth muscles and has been reviewed elsewhere, and see Fig. 2 (Wray \& Prendergast 2019). The interaction of myosin heads with actin filaments is the culmination of a pathway that starts with excitation of the myocyte membrane and opening of voltage-dependent L-type $\mathrm{Ca}^{2+}$ channels (Shmigol et al. 1998). Excitation may be initiated by specialised

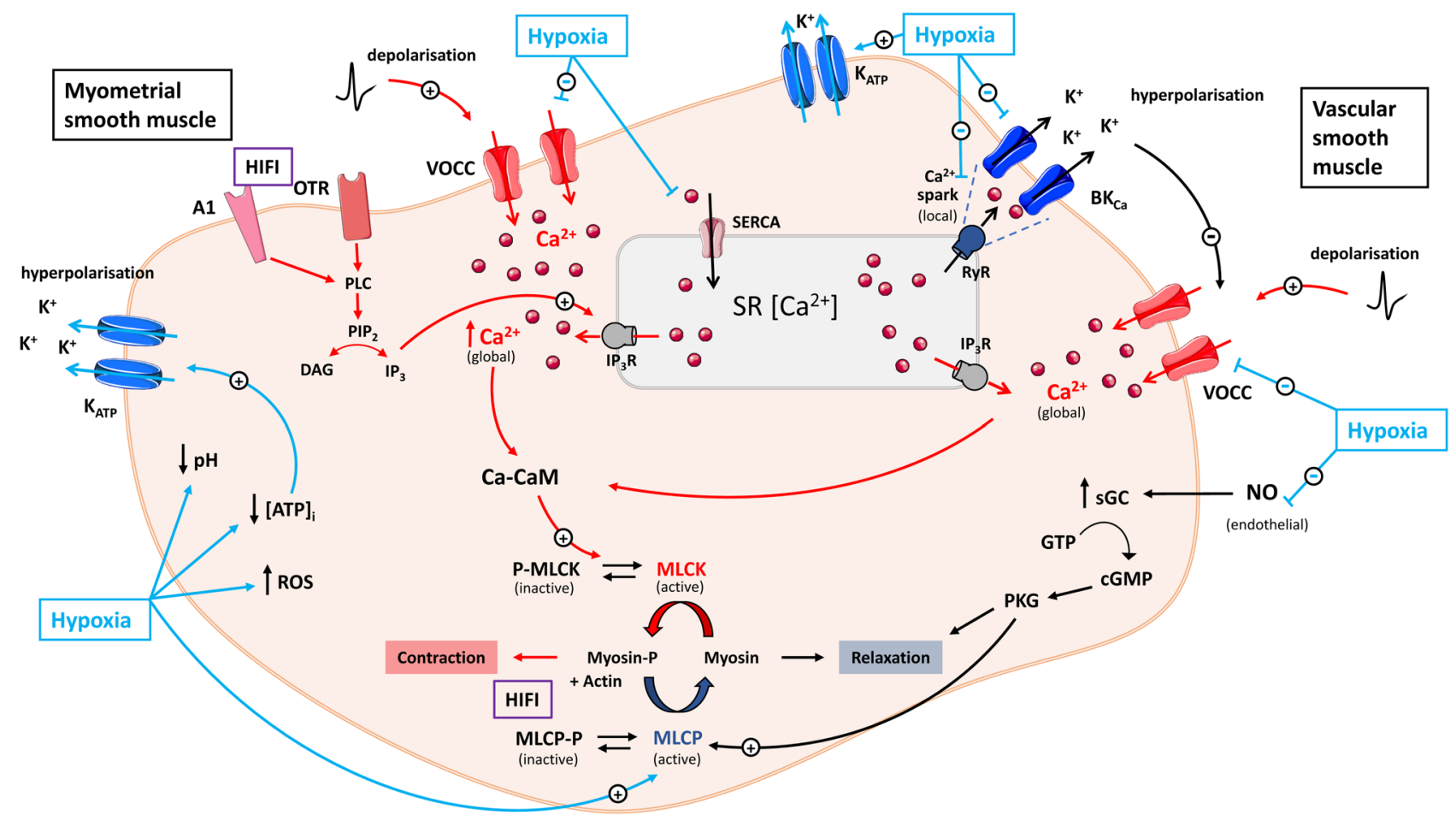

Figure 2 Signalling pathways controlling contraction and relaxation of myometrial and vascular smooth muscle and effects of hypoxia. In smooth muscle (SM), action potentials depolarise the membrane causing opening of voltage-operated calcium channels $(\mathrm{VOCC})$ and $\mathrm{Ca}^{2+}$ influx. Agonists, such as oxytocin and adenosine, also cause a rise in $\left[\mathrm{Ca}^{2+}\right]_{\mathrm{i}}$. Ca ${ }^{2+}$ combines with calmodulin, activates myosin light-chain kinase (MLCK), resulting in cross-bridge cycling and contraction. Relaxation occurs when $\left[\mathrm{Ca}^{2+}\right]_{i}$ falls or when myosin light-chain phosphatase (MLCP) activity exceeds MLCK activity. In vascular SM, $\mathrm{Ca}^{2+}$ sparks activate $\mathrm{BK}_{\mathrm{Ca}}$ channels, leading to hyperpolarisation, inhibition of $\mathrm{VOCC}$ and thus relaxation. Endothelial NO causes cGMP-mediated relaxation of vascular SM. Red arrows indicate contraction pathways via a rise in $\left[\mathrm{Ca}^{2+}\right]_{i}$. Black arrows indicate relaxing pathways. Labour contractions occlude vessels, producing hypoxia, resulting in oxidative stress, decreased $\mathrm{pH}$ and $[\mathrm{ATP}]$. Hypoxia modulates $\left[\mathrm{Ca}^{2+}\right]_{\mathrm{i}}$ and thus contraction by inhibiting VOCC, activating $\mathrm{K}_{\mathrm{ATP}}$ channels, altering SR activity, inhibiting $\mathrm{Ca}^{2+}$ sparks and $\mathrm{BK}_{\mathrm{Ca}}$ activity. Hypoxia inhibits $\mathrm{NO}$ production. In myometrium, brief repetitive bouts of hypoxia, acting, for example, on adenosine receptors (A1), can increase force, HIFI. Hypoxia also has $\mathrm{Ca}^{2+}$-independent effects, leading to increased MLCP activity. Blue arrows indicate where hypoxia affects these pathways. A1, adenosine receptor 1; Ca-CaM, $\mathrm{Ca}^{2+}$-calmodulin complex; HIFl, hypoxia-induced force increase; $I_{3} R$, IP 3 receptor; PLC, phospholipase C; PKG, protein kinase G; SR, sarcoplasmic reticulum; sGC, soluble guanylyl cyclase; ROS, reactive oxygen species; RyR, ryanodine receptor. With thanks to Dr Sarah Arrowsmith for giving us the cell template. 
myocytes acting as pacemakers, causing depolarisation, and thus, opening of L-type channels (Lutton et al. 2018). The action potential in human myometrium propagates over a distance of a few $\mathrm{cm}$ and additional mechanisms, such as mechanotransduction (Young 2016) may be needed for contractions to be synchronised throughout the myometrium. The resulting rise in $\left[\mathrm{Ca}^{2+}\right]$ leads to formation of Ca-calmodulin complex. This complex combines with, and switches, myosin light chain kinase (mlck) to its active form, promoting phosphorylation of the regulatory light chains of myosin. This activates the myosin head ATPase, actin attachment and crossbridge cycling. Contraction occurs and is followed by relaxation as $\left[\mathrm{Ca}^{2+}\right]$ falls due to $\mathrm{Ca}^{2+}$ channel inactivation, mlck dissociating from 4Ca-calmodulin, and mlc phosphatase (mlcp) removing the phosphate group from the light chains. In this way phasic contractions, governed by changes in excitability and thus $\left[\mathrm{Ca}^{2+}\right.$, occur. In labour the increased strength, duration and frequency of contractions is due to the action potential changing from spike-like to plateau type, leading to increased $\mathrm{Ca}^{2+}$ entry, and increased firing of action potentials. Unlike myometrial arterial smooth muscle, the relaxing role of $\mathrm{Ca}^{2+}$, mediated via the $\mathrm{Ca}^{2+}$-sparksSTOCs pathway is not present in the smooth muscle of the myometrium itself (Shmigol et al. 1999, Burdyga et al. 2007, Noble et al. 2014). Calcium release from the SR occurs via $\mathrm{IP}_{3}$ binding and can augment agonist contractions (Arrowsmith \& Wray 2014). Both vascular and myometrial contractility requires ATP, and thus metabolism and blood flow are discussed next.

\section{Myometrial metabolism}

\section{Overview}

Glucose appears to be the only energy substrate used by the human pregnant myometrium (Steingrímsdóttir et al. 1993). A significant amount of this glucose is consumed through the anaerobic pathway, resulting in lactate production, even when oxygen is not limited and the tissue is contracting at basal rates (Wray 1990, Steingrímsdóttir et al. 1997). A five-fold increase in lactate efflux occurs with metabolic inhibition (Wray 1990). It remains unclear why the anaerobic glycolytic pathway is part of the normal metabolism of myometrium, but compartmentation of ATP production between excitability (glycolytic) and oxidative (contractile) demands has been suggested (Campbell \& Paul 1992). Interestingly, recent work in uterus and other tissue has shown that extracellular lactate has signalling roles (Brooks 2020). In the myometrium, lactate binding to its receptor-stimulated anti-inflammatory pathways (Madaan et al. 2017).

As first reported in pregnant rats (Dawson \& Wray 1985) and then human (Steingrímsdóttir et al. 1997), [ATP] is $\sim 3 \mathrm{mM}$ and phosphocreatine (PCr) concentration is $3-5 \mathrm{mM}$. As with other smooth muscles, these values, especially $[\mathrm{PCr}]$ are low compared to striated muscles, where it is present at around $30-40 \mathrm{mM}$.

Contractions in smooth muscle are energetically economical and relatively slow, and thus the [PCr] can maintain [ATP] and support myometrial contractions under the normal conditions. Animal studies have demonstrated however, that even modest decreases in blood flow affects metabolite concentrations; ATP and phosphocreatine $(\mathrm{PCr})$ decrease, while inorganic phosphate $(\mathrm{Pi})$ and lactate increase (Larcombe-McDouall et al. 1998).

\section{Myometrial preparation for hypoxia at term}

The human myometrium at term is prepared for hypoxia. It lays down metabolic reserves including glycogen and fatty acid droplets (Wynn 1967, Milwidsky \& Gutman 1983). In hypoxia, glycogenolysis will produce ATP using glycogen and producing lactate. A switch occurs with the expression of isoforms of lactate dehydrogenase (LDH) which are least inhibited by product (i.e. lactate) at term (Makkonen et al. 1982). There are also modest increases in $[\mathrm{ATP}]$ and $[\mathrm{PCr}]$ at term in rat myometrium (Dawson \& Wray 1985). Thus, the term-pregnant myometrium is better able to withstand hypoxic episodes, than nonpregnant. Given the low reserves of PCr in myometrium, we speculate that creatine supplementation may improve labour outcome. In mice, this approach has led to improved neuronal outcomes after induced hypoxia, but it is unclear whether improved contractions and delivery contribute to this cerebral effects (Ireland et al. 2011).

\section{Myometrial pH}

A switch to anaerobic respiration under hypoxic conditions, increases lactate production in vascular and myometrial smooth muscles (Lovgren \& Hellstrand 1985, Wray 1990) and leads to intracellular acidification. A direct concentration-dependent effect of lactate on myometrial intracellular $\mathrm{pH}\left(\mathrm{pH}_{\mathrm{i}}\right)$ has been measured (Hanley et al. 2015), and under normoxic conditions, inhibition of lactate efflux will cause acidification (Wray 1990). Changes in $\mathrm{pH}_{\mathrm{i}}$ in myometrial smooth muscles are limited by buffering and $\mathrm{pH}$ regulatory mechanisms (e.g $\mathrm{Na}^{+} / \mathrm{H}^{+}$exchanger) (Little et al. 1995). In myometrium buffering capacity $\left(\Delta \mathrm{H}^{+} / \Delta \mathrm{pHi}\right)$, has been calculated to be $\sim 40$, and the main contributors to it are bicarbonate, proteins and phosphates (Bullock et al. 1998). However, changes in $\mathrm{pH}_{\mathrm{i}}$ will occur, especially if flow is restricted, such that external $\mathrm{pH}$ also falls. Intracellular acidification has been demonstrated in myometrium in vivo and in vitro during ischemia and hypoxia, respectively (Larcombe-McDouall et al. 1998). Furthermore, in vivo and in vitro, in pregnant rat myometrium, acidification occurs during each contraction, and is proportional to the strength of contraction (Taggart \& Wray 1993, 
Larcombe-McDouall et al. 1999), with $\mathrm{pH}_{\mathrm{i}}$ recovering during the relaxation between contractions.

The mechanisms leading to the fall in myometrial $\mathrm{pH}$ with contraction are a mixture of changes of metabolic pathways, utilisation of metabolic reserves and accumulation of waste products (Taggart \& Wray 1998). Initially, PCr breakdown maintains ATP in a reaction which is net proton absorbing, but is followed by net generation of protons, due to elevated lactate production, as metabolism shifts from aerobic to anaerobic. Anaerobic metabolism is stimulated because the contraction reduces its own blood supply.

\section{Hypoxia in the myometrium}

\section{Uterine contractions reduce blood flow}

The force generated by the contractile bundles in the myometrium during labour compresses the vessels lying within. This squeeze decreases inflow of blood, producing local transient ischemia and hypoxia and a switch from aerobic to anaerobic respiration, in the myometrial (and vascular) myocytes (LarcombeMcDouall et al. 1999).

Thus, during labour myometrial contractions decrease uterine blood flow, which recovers when the muscle relaxes (Greiss 1965, Brotanek et al. 1969, Brar et al. 1988). In women, this was first demonstrated using invasive methodologies (Borell et al. 1964, Brotanek et al. 1969) and confirmed using modern imaginingbased techniques, for example, 3D power Doppler angiography (Jones et al. 2009). These data confirm reduced perfusion during uterine contractions in women in spontaneous labour. Such decreased blood flow will be expected to produce hypoxia. The extent of the hypoxia in women has not been quantified, but surrogates for hypoxia, such as a fall in $\mathrm{pH}$ and increased lactate from switching to anaerobic respiration, have, and in vivo studies in pregnant rats, found these and other metabolic parameters, all correlate well with the degree of occlusion of uterine vessels (LarcombeMcDouall et al. 1999). Thus, we can speculate that oxygenation during the peaks of contractions and before restoration of perfusion, will reduce by $50 \%$

\section{Fetal hypoxia in labour due to myometrial activity}

The decrease in blood flow with each contraction is transmitted to, and detected by, the fetus, as there is a decrease in the placental blood flow which causes a less efficient gas and nutrient exchange, that can be detected by the fetus. This stimulates an increase of heart rate as force peaks. If, however, the myometrial contractions are too frequent, long-lasting or strong, then the changes to foetal blood delivery become more challenging and can lead to foetal distress and the need for an operative delivery. The effects of uterine contractions in women on foetal cerebral oxygenation were shown using nearinfrared spectroscopy, and as with uterine flow, an inverse relationship was found (Peebles et al. 1994). Over-administration of oxytocin, which can occur in cases of slow to progress labours, will also cause foetal distress due to excessive stimulation of the myometrium. Tonic-like contractions, whether caused by oxytocin or on occasion, spontaneously, greatly impair uterine perfusion.

\section{Hypoxia and contractions}

Contractions in human labour are of variable length, but generally last 2-4 min; those of rodents are an order of magnitude shorter and their frequency is greater than in women. Evidence from animal and human myometrial studies is clear; hypoxia can decrease myometrial contractility. In pregnant rat and human myometrium, blocking oxidative phosphorylation, for example, with cyanide, reduced spontaneous and agonist-augmented contractions (Wray 1990). Hypoxia per se was first shown to decrease contractions in biopsies of pregnant human myometrium (Monir-Bishty et al. 2003). This finding was extended by Bugg et al., who also showed hypoxia decreased force in non-pregnant myometrium and in the presence of oxytocin (Bugg et al. 2006). Thus, agonists slow, but do not prevent, the fall in force in the myometrium during hypoxia.

\section{Mechanism}

With hypoxia, as shown in Fig. 2, $\mathrm{Ca}^{2+}$ entry is decreased secondary to reduced excitability of the myometrium. This points to decreased oxygenation directly increasing $\mathrm{K}^{+}$channel conductance, causing hyperpolarisation, and/or inhibiting channels producing depolarisation, that is, VOCC or $\mathrm{Ca}^{2+}$-activated chloride channels (Jones et al. 2004). The effects of hypoxia on ion channels may be secondary to changes of [ATP], $\mathrm{pH}$ and formation of reactive oxygen species (ROS).

A fall in [ATP] will activate ATP-gated $\mathrm{K}^{+}$channels $\left(\mathrm{K}_{\mathrm{ATP}}\right)$, and $[\mathrm{ADP}]$ and $\mathrm{pH}$ modulate their conductance. This makes $K_{\text {ATP }}$ channels good candidates for sensing metabolic changes and converting them into changes in excitability. They are abundant in myometrium (Teramoto 2006), but expression decreases at term (Sawada et al. 2005, Xu et al. 2011). In pregnant human myometrium, $\mathrm{K}_{\text {ATP }}$ channel openers inhibit spontaneous and oxytocin-stimulated contractility (Longo et al. 2003), but are less potent in myometrium from women in labour than those not in labour (Xu et al. 2011). Glibenclamide, an antagonist of $\mathrm{K}_{\text {ATP }}$ channels, has little effect on spontaneous or oxytocin-stimulated uterine contractions, nor does it modify in vivo activity (Piper et al. 1990). This suggests that $K_{\text {ATP }}$ are closed at rest, do not contribute to resting membrane potential but open during metabolic stress. We tested this in rat myometrium, 
by using cyanide to reduce [ATP] and measured $\mathrm{K}^{+}$ efflux. The decrease of contractility was accompanied by increased $\mathrm{K}^{+}\left({ }^{86} \mathrm{Rb}\right)$ efflux (Heaton et al. 1993). Of this increase, about $50 \%$ occurred through $\mathrm{K}_{\text {ATP }}$ channels, and the hyperpolarisation this will produce, contributes to the fall in force.

In summary, the evidence shows that during prolonged hypoxia the abolition of contractions is likely due to hyperpolarisation produced by opening of a variety of $\mathrm{K}^{+}$channels, and decreased $\mathrm{Ca}^{2+}$ entry.

\section{Hypoxia-induced force increase, HIFI, in labouring myometrium}

The previous in vitro studies of hypoxia or metabolic inhibition were conducted under conditions of a single, continued experimental intervention for tens of minutes. In labour, however, hypoxia will be briefer, lasting around a minute, but repeated many times. Recent work using a repetitive pattern of brief hypoxic episodes produced an exciting finding; force increased (Alotaibi et al. 2015).

Repetitive, brief (2-5 min) episodes of hypoxia to rat myometrium increased contraction force; the contractility fell during hypoxia but on return to normoxia gradually increased following successive hypoxic periods. We named this phenomenon hypoxiainduced force increase (HIFI) (Alotaibi et al. 2015). HIFI will be important in labour as: (1) it only occurs at term or in labour, (2) occurs in rat and human myometrium, (3) HIFI occurs in the presence of oxytocin, and further augments contractility, and can increase force when oxytocin receptors are blocked, (4) HIFI is long-lasting and, once primed, the increase of force is maintained for up to $12 \mathrm{~h}$.

We have suggested that HIFI is a novel mechanism, produced by hypoxia, underlying the strengthening of labour contractions. Evidence for HIFI in vivo in women is hard to obtain, as it is intrinsic to the labouring myometrium. There is evidence for HIFI in vivo in pregnant rats: a HIFI-like increase of contractile force followed episodes of uterine artery occlusion and reperfusion (Harrison et al. 1995).

When considering the effects of hypoxia on the labouring myometrium, it is now clear that we need to distinguish between the acute strengthening effects of $\mathrm{HIFI}$, and the weakening effects of prolonged hypoxia. The mechanisms underlying the repetitive, transient effects on contraction are likely to be different from those producing the chronic effects of hypoxia and are discussed next.

\section{Mechanism of HIFI}

Given that HIFI increases force, it was anticipated that it would increase $\mathrm{Ca}^{2+}$ entry, but simultaneous measurements of force and $\mathrm{Ca}^{2+}$ did not show this
(Alotaibi et al. 2015). Investigations of intracellular pathways however showed that both adenosine and prostaglandins were important. Enhancement of these (and probably other) stimulatory pathways by HIFI, and the promotion of mlck activity, and/or decreased mlcp would be expected to promote force (Fig. 2). It was also found that external acidification, but not alkalinisation, could reproduce HIFI, but not as powerfully as hypoxia. There are acid-sensitive ion channels expressed in myometrium. The TASK channels encoded by KCNK3 and $\mathrm{KCNK9}$, in human myometrium, decrease their conductance with extracellular acidification (Duprat et al. 1997) and hypoxia. Two recent papers have shown in mouse myometrium that TASK2 channel inhibitors stimulate contraction, as does acidic $\mathrm{pH}$ (Hong et al. 2013, Kyeong et al. 2016). Acid-sensitive channels related to $\mathrm{ENaC}$ may also contribute, but little is known about these in myometrium (Boscardin et al. 2016). Thus, these acid-sensitive channels could be part of a mechanism such as HIFI, to keep labour progressing when hypoxic conditions arise.

\section{Hypoxia and labour \\ Hypoxia and normal labour}

The phasic contractions of labour produce hypoxia. As discussed, the term pregnant myometrium has increased its metabolic reserves and capacity to withstand hypoxia, and the HIFI mechanism adds to the contractile drive. The periods of muscle relaxation between contractions allow for reoxygenation of the tissues and removal of waste products from the myocytes. During labour, lasting for hours, the contractions build, until the cervix is fully dilated, and the baby, then umbilical cord and placenta delivered.

However, not all term-labours proceed well but instead arrest with the cervix incompletely dilated. Until relatively recently there were no data to explain why around $10 \%$ of births had contractions so poor, as to be incapable of dilating the cervix. These slow to progress, dysfunctional labours, are the leading cause of unplanned Caesarean sections, a source of trauma to women, contributors to neonatal complications, and a financial burden to healthcare systems.

\section{Hypoxia and dysfunctional labour}

We are focussing on physiological causes of dysfunctional labour, rather than obstructed labours (Neilson et al. 2003). The first clinical and physiological insight into dysfunctional labour came when myometrial capillary blood was analysed from women having Caesarean sections for a variety of reasons (Quenby et al. 2004). Based on the in vitro studies showing hypoxia and low $\mathrm{pH}$ can decrease uterine contractility, we tested the maternal blood for $\mathrm{pH}$ and lactate. The 
results were clear; those labouring dysfunctionally had a more acidic blood than any other group (Quenby et al. 2004). Furthermore, the myometrial capillary blood, had significantly increased lactate, but there was no systemic acidosis or hypoxia. This suggested that in some women, hypoxia was detrimental to contractions. Under these circumstances, oxytocin is unlikely to overcome the poor, hypoxic myometrial environment - thus, these women required surgical delivery of their babies (Wiberg-Itzel et al. 2014). This is consistent with the in vitro findings of hypoxia on contractility in human myometrium; oxytocin cannot prevent the fall of force (Bugg et al. 2006).

\section{Lactate as a predictor of dysfunctional labour}

Another breakthrough in establishing a link between hypoxia and poor contractions in labour came from a study measuring lactate in amniotic fluid at the start of active labour and when labour arrested (Wiberg-Itzel et al. 2010). The investigators reasoned that high levels of lactate in dysfunctionally labouring myometrium would be reflected in the amniotic fluid. Collecting leaking amniotic fluid at the start of labour, established a range of values. Importantly, a lactate concentration above a threshold level was predictive of women who would labour dysfunctionally (Wiberg-Itzel et al. 2009, 2014). The authors conclude that amniotic fluid lactate levels $>10.1 \mathrm{mmol} / \mathrm{L}$ has sensitivity of $39 \%$ and specificity of $90.3 \%$, for detecting women who need a caesarean section (Wiberg-Itzel et al. 2016). Such a predictive test has utility in preparing the mother and clinical team, and guiding care. A recent extension of this work is the measurement of lactate in foetal scalp blood (Iorizzo et al. 2019).

\section{pH and dysfunctional labour}

Better however than prediction would be prevention. A recent clinical trial suggests that combatting the acidosis produced by excessive lactate levels in women labouring dysfunctionally, would be successful (WibergItzel et al. 2018). The in vitro and in vivo work discussed earlier shows that hypoxia during contractile activity is associated with a fall in $\mathrm{pH}$, which can decrease force (Crichton et al. 1993, Austin \& Wray 1994, Harrison et al. 1994, Taggart et al. 1997), and change the contraction pattern to one resembling a dysfunctional labour (Pierce et al. 2003). If, however, in these in vitro studies, the acidic $\mathrm{pH}$ change produced by lactate was nulled, by simultaneously applying a weak base $\left(\mathrm{NH}_{4} \mathrm{Cl}\right)$, then force no longer fell (Hanley et al. 2015). The conclusion from this work was that elevated lactate in myometrium decreases force by acting as a weak acid. If the fall in $\mathrm{pH}$ can be prevented, then lactate will not reduce force. Putting these findings together, we hypothesized that labour outcome in women labouring dysfunctionally would be improved if we reduced the acidification present in the myometrium. In this blinded randomised trial, women in their first labour, with a clinical diagnosis of dystocia, were either given the standard treatment, oxytocin, or a drink containing bicarbonate, followed an hour later by oxytocin. There was a statistically significant increase in the number of women who had a vaginal rather than operative delivery, in the women administered bicarbonate to decrease the lactic acidosis in their myometrium (Wiberg-Itzel et al. 2018).

Having made significant progress in understanding how hypoxia is an important determinant of dysfunctional labours, the next part of the puzzle becomes, why do only some women encounter excessive hypoxia and acidification?

\section{Why do only some women have dysfunctional labours?}

Researchers have worked to determine which maternal factors might lead to a dysfunctional labour (Zhang et al. 2007, Wray \& Arrowsmith 2012). The data can be summarised as: some factors, such as obesity, age, diabetes, can increase the risk, none are predictive - young, fit, lean women also suffer unexplained dysfunctional labours. There is evidence for familial inheritance dysfunctional labour, but it cannot explain most cases (Algovik et al. 2010).

\section{Transcriptional studies}

In considering the link with hypoxia, it is known that many genes involved in metabolism and contraction are regulated by hypoxia. A key driver of this is hypoxiainducible factor (HIF1A), a powerful transcription factor, which forms during hypoxia. Described as the master regulator of responses to hypoxia, it leads to the switching on of hundreds of genes, including those associated with angiogenesis, metabolism, $\mathrm{pH}$ regulation, apoptosis and endothelial homeostasis (Loboda et al. 2010). HIF1 expression is increased in ovine uterine arteries with chronic hypoxia (Xiao et al. 2013). To date, three studies have compared the myometrial transcript of women who had a dysfunctional labour and those who laboured successfully (Brennan et al. 2011, Mittal et al. 2011, Chaemsaithong et al. 2013). They report differential gene expression and two showed that HIF1 expression is increased in term pregnant labouring women with arrest of descent or dilation compared with normally labouring women. Genes linked to inflammation and contractility were also reported altered in all three studies. Of note, Mittal et al found that one of the most marked changes was increased IL6 (interleukin 6) mRNA and protein. As muscle-derived IL6 increases in response to reduced intramuscular glycogen content (Shephard 2002), this suggests that myometrial glycogen stores are being depleted. It would be of interest to 
know whether glycogen stores are lower at the start of labour in women who go on to labour poorly. Thus, from the studies so far, genes connected with hypoxia and inflammatory changes seem to be associated with dysfunctional labour, but more work is required in identifying causal relationships. For example, are some women expressing fewer transporters for lactate, or $\mathrm{pH}$ regulatory mechanisms, such that their myometrium builds up an environment that is hostile to contractions? Are there genetic differences leading to reduced glycogen deposition or utilisation, leading to exhaustion?

\section{Role of the vasculature in dysfunctional labour}

\section{Background}

This review started by exploring the relation between the myometrium and its blood supply, and documenting the repetitive compression of these vessels. The vital restoration of flow and with it metabolites, occurs between contractions. Here we address whether a failure in perfusion could create the conditions that lead to dysfunctional labour, and start by asking what hypoxia does to myometrial blood vessels, then discuss two specific features of the circulation; reactive hyperaemia and preconditioning, in relation to myometrial hypoxia and labour. We finish with how the maternal phenotype may contribute to dysfunction.

\section{Hypoxia vascular smooth muscle}

The effect of hypoxia on vascular smooth muscle function (Fig. 2) has been extensively studied and reviewed in peripheral vessels (e.g. Austin \& Wray 1995, 2000, Smith et al. 1998) although studies focused on myometrial/ uterine vessels tend to have only examined the effect of chronic hypoxia. Hypoxia produces varying responses depending on the vascular bed and on the length of the period of decreased $\mathrm{O}_{2}$ supply. Acute hypoxia generally relaxes systemic vessels, a protective response to increase blood flow to endangered peripheral tissues, while the pulmonary vasculature vasoconstricts to divert blood from poorly ventilated to well-ventilated lung. Human fetoplacental vessels similarly constrict under low $\mathrm{O}_{2}$ conditions (Howard et al. 1987). Many studies have demonstrated that hypoxia-induced vasodilatation occurs because of decreases in $\left[\mathrm{Ca}^{2+}\right]_{i}$ in the peripheral vessels (Pearce et al. 1992, Smani et al. 2002). As discussed for myometrium, hypoxia decreases $\left[\mathrm{Ca}^{2+}\right]_{\mathrm{i}}$ in vascular myocytes via effects on calcium channels, VOCC, (Herrera \& Walker 1998), SR (Guibert et al. 2002), or indirectly, by stimulating $\mathrm{K}^{+}$channels causing hyperpolarisation. The $\mathrm{K}^{+}$channels involved include, $K_{\text {ATP }}$ (Shimoda \& Polak 2011), voltage-dependent $\mathrm{K}^{+}$ (Hedegaard et al. 2014) and $\mathrm{BK}_{\mathrm{Ca}^{\prime}}$ (Gebremedhin et al. 1994). Decreased $\mathrm{Ca}^{2+}$ spark frequency in myometrial arteries, would increase tone, compromising blood flow to the placenta and limiting myometrial recovery between contractions. Hypoxia can also cause relaxation of vascular smooth muscle via $\mathrm{Ca}^{2+}$-independent methods (Aalkjaer \& Lombard 1995). There appear to be no direct studies investigating how acute hypoxia affects human myometrial vessels.

In uterine arterial smooth muscle from pregnant animals, it has been shown that chronic hypoxia suppresses agonist-mediated contractile responses and intracellular $\mathrm{Ca}^{2+}$ mobilisation (Zhang \& Xiao 1998), decreases $K_{\text {ATP }}$ channel (Xiao et al. 2010) and BK channel activity (Kazmierczak et al. 2013) and increases ROS production (Kazmierczak et al. 2013).

\section{Reactive hyperemia}

After a tissue has been deprived of oxygen (arterial occlusion or peripheral compression), reactive hyperaemia is the process by which blood flow to that tissue is increased, to restore oxygen levels (Bliss 1998). The extent and duration of the increased flow increases with the duration of occlusion but varies between vascular beds. Reactive hyperaemia occurs in uterine vessels. It has been observed in sheep uterine arteries, albeit stronger in non-pregnant than pregnant sheep (Fleet \& Heap 1982). In rat, it is seen following 15\% of uterine artery occlusions (Larcombe-McDouall et al. 1998). In pregnant women, no evidence of reactive hyperaemia was found (Jones et al. 2009). In brachial arteries, reactive hyperaemia is reduced in pregnancy (Dorup et al. 1999), perhaps because blood vessels are already more dilated than usual. The fundamental stimulus driving reactive hyperaemia is tissue hypoxia and $\mathrm{K}_{\text {ATP }}$ channels, adenosine, $\mathrm{NO}$ and prostaglandins have all been implicated. Repeated vessel occlusions decrease reactive hyperaemia when the inter-stimulus interval is short (Eikens \& Wilcken 1973, Turturici \& Roatta 2013, Messere et al. 2017). This may be relevant to labour when the contraction frequency is high.

\section{Ischaemia-reperfusion and hypoxic preconditioning}

Reperfusion of tissues following a period of ischemia is vital for tissue viability and function, but reintroduction of oxygen can paradoxically cause further damage. This is due to loss of ionic balance, oedema and the generation of ROS and inflammatory cytokines, (Gourdin et al. 2009). The endothelium is very sensitive to such injuries, producing a reduction in NO-mediated vasodilation and vasospasm (Gourdin et al. 2009). Intermittent hypoxia impairs uterine artery function in pregnant mice and increases markers of oxidative stress and inflammation (Badran et al. 2019). Indeed, ROS significantly inhibit myometrial contraction (Kirby et al. 2005) and therefore hypoxia-induced ROS production may lead to poorer myometrial contractions and thus contribute to dysfunctional labour. 
The phenomenon of hypoxic preconditioning has been observed in some smooth muscles (Almohanna \& Wray 2018), where exposure to small periods of hypoxia can provide resistance to a subsequent larger ischaemic insult. Protection of the endothelium is a major part of this mechanism in human (Corcoran et al. 2018). Hypoxic preconditioning has not been directly demonstrated in myometrial arteries, though based on other vascular beds, we might surmise that it should protect them. The repeated contractions of labour generate repeated ischaemia-reperfusion events and while we have seen that this can enhance the contraction of term pregnant myometrium (HIFl; Alotaibi et al. 2015), it is also clear that labour contractions generate oxidative stress, proinflammatory cytokines and apoptosis in placentas of women undergoing vaginal deliveries compared to non-labouring caesarean sections (Cindrova-Davies et al. 2007).

\section{Maternal phenotype}

It has become clear that maternal phenotype (e.g. BMI, diabetes, age) can have a detrimental effect on human myometrium (Al-Qahtani et al. 2012, Arrowsmith et al. 2012, Carlson et al. 2015, Wray 2015). The myometrial arteries from obese mothers exhibit deficits in endothelial cell calcium signalling and the eNOS system (Prendergast \& Wray 2019), and alterations to both contractile and relaxation responses (Hayward et al. 2014). Myometrial arteries from diabetic mothers exhibit a deficit in endothelial-dependent relaxation (Fleischhacker et al. 1999, Chirayath et al. 2010) and hyperreactivity of vascular smooth muscle (Fleischhacker et al. 1999). Both conditions are associated with a higher risk of dysfunctional labour and caesarean section (Prendergast 2020). Smoking can also adversely affect myometrial artery function (Andersen et al. 2011). The process of labour puts a strain on the myometrial vasculature and the ability of these vessels to adapt to conditions of intermittent hypoxia/changing $\mathrm{pH}$ will be instrumental in successful parturition. An evergrowing proportion of the population exhibit obesity/ diabetes and the underlying vascular dysfunction in this population may make it harder to withstand the rigours of labour and risks further elevating the proportion of dysfunctional labours that require intervention or caesarean section. Dyslipidaemias associated with obesity and diabetes affect myometrial membrane microdomains (Draeger et al. 2005), which in turn affects ion channels and signalling (Noble et al. 2006, Shmygol et al. 2007).

\section{Future research}

It is clear that there are gaps in our knowledge concerning hypoxia in labour and new questions arising following recent research findings. The difficulties of obtaining data in pregnant women are obvious, and animal models naturally have their limitations. It would be a large step forward if we have proteomic and metabolomic data on the acute and long-term effects of hypoxia on the myometrium. These findings could then be linked to signalling pathways, including those illustrated in Fig. 2, but also associated with inflammation, and, importantly, unexpected candidates arising from such studies, investigated. These approaches could be linked to transcriptomic studies from women in normal and dysfunctional labours (Chaemsaithong et al. 2013). We also recommend in turn that there is a resurgence of

\section{Relation between contractions, blood flow and labour}

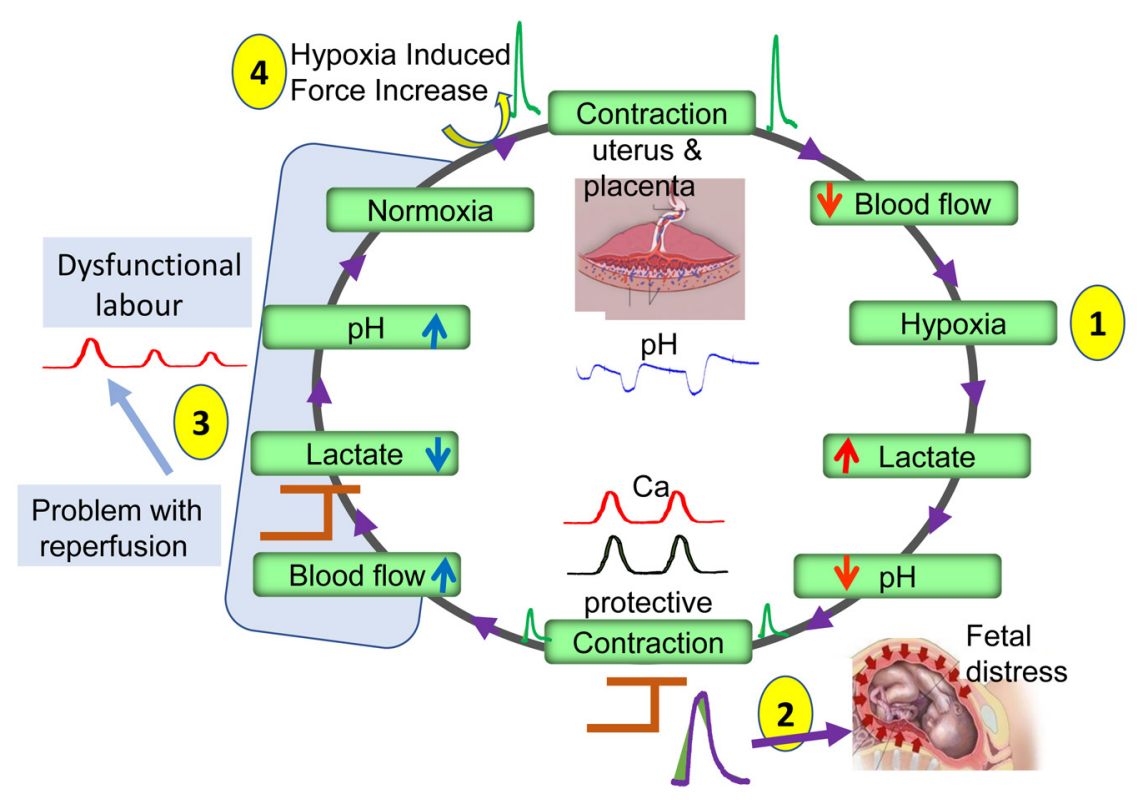

Figure 3 Relationship between contraction, hypoxia and labour. (1) Contractions occlude blood vessels, producing hypoxia, increased lactate, and a fall in $\mathrm{pH}$. (2) These changes decrease the strength and duration of the contraction, protecting the fetus from hypoxia. Perfusion is restored as the contraction relaxes, and the myometrial metabolites and $\mathrm{pH}$ are restored. (3) If the blood vessels do not fully recover, normal metabolites and $\mathrm{pH}$ will not restore, and subsequent contractions will be poor and the labour dysfunctional. (4) In normal labours many cycles of moderate hypoxia occur and engender HIFI (hypoxiainduced force increase), which help maintain and increase contractility until the end of labour. 
studies with more refined assays detailed the biochemical and metabolic activity of human myometrium and relating this to labour outcomes. For example, how and when do glycogen or fatty acid deposit build in human myometrium, and what are the consequences for labour if these are inadequate. Similarly, we lack an understanding of lactate transporters in human myometrium (Åkerud et al. 2009) or how switches in lactate dehydrogenase isoenzymes occur and the functional consequences of aberrant shifts (Makkonen et al. 1982). As indicated previously, we are missing much specific information on myometrial blood vessels. These could hold the key to future therapeutic targets. A more in-depth knowledge of all these interactions stemming from hypoxia in labour is required, that can then be personalised with effective interventions and therapies, that will enable women to have better labours and their babies, a better birth. That oral bicarbonate study (Wiberg-Itzel et al. 2018), powerfully demonstrates that when such knowledge of the physiology of labour is obtained, it can be translated.

\section{Conclusions}

The outcome of the intermittent hypoxia of labour will be a balance between the force enhancing effects on the myometrium and the detrimental oxidative, metabolic and inflammatory stress response experienced by the smooth muscle of the vasculature and myometrium. This balance is intimately related to the success of human parturition. There will be a subset of pregnancies including those with abnormal placental development, that cannot withstand the rigours of labour (Turner et al. 2020).

As shown in Fig. 3, the myometrial metabolite changes, especially $\mathrm{pH}$ that arise from hypoxia (1), will feedback during the contraction to prevent tonic activity, and protect the fetus from hypoxic distress (2). If the myometrial vessels do not recover from the repetitive compressions, then products of anaerobic metabolism will build, metabolites are not restored as reserves such as glycogen are exhausted. These changes are associated with dysfunctional labours (3). If blood vessels restore perfusion, metabolites, $\mathrm{pH}$ and excitability return to normal levels and the next labour contraction occurs. The effect of the hypoxia will also trigger changes in myometrial signalling pathways, such as that produced by purinergic agonists, that gradually and safely augment contractions, HIFI (4).

\section{Declaration of interest}

The authors declare that there is no conflict of interest that could be perceived as prejudicing the impartiality of this review.

\section{Funding}

S W is grateful to the Harris Wellbeing of Women research centre for support. M A gratefully acknowledges support from The Northern Border University, Arar, KSA, and C P gratefully acknowledges support from The University of Liverpool.

\section{Author contribution statement}

S W conceived the structure. S W, M A and C P drafted the text. S W and C P edited the text.

\section{Acknowledgements}

S W is grateful to the Harris Wellbeing of Women research centre for support, $\mathrm{M}$ A gratefully acknowledges support from The Northern Border University, Arar, KSA, and C P gratefully acknowledges support from The University of Liverpool.

\section{References}

Aalkjaer C \& Lombard JH 1995 Effect of hypoxia on force, intracellular $\mathrm{pH}$ and $\mathrm{Ca}^{2+}$ concentration in rat cerebral and mesenteric small arteries. Journal of Physiology 482 409-419. (https://doi.org/10.1113/ jphysiol.1995.sp020528)

Åkerud H, Ronquist G \& Wiberg-Itzel E 2009 Lactate distribution in culture medium of human myometrial biopsies incubated under different conditions. American Journal of Physiology: Endocrinology and Metabolism 297 E1414-E1419. (https://doi.org/10.1152/ ajpendo.00458.2009)

Algovik M, Kivinen K, Peterson H, Westgren M \& Kere J 2010 Genetic evidence of multiple loci in dystocia - difficult labour. BMC Medical Genetics 11 105. (https://doi.org/10.1186/1471-2350-11-105)

Almohanna AM \& Wray S 2018 Hypoxic conditioning in blood vessels and smooth muscle tissues: effects on function, mechanisms, and unknowns. American Journal of Physiology: Heart and Circulatory Physiology 315 H756-H770. (https://doi.org/10.1152/ajpheart.00725.2017)

Alotaibi M, Arrowsmith S \& Wray S 2015 Hypoxia-induced force increase $(\mathrm{HIFI})$ is a novel mechanism underlying the strengthening of labor contractions, produced by hypoxic stresses. PNAS 112 9763-9768. (https://doi.org/10.1073/pnas.1503497112)

Al-Qahtani S, Heath A, Quenby S, Dawood F, Floyd R, Burdyga T \& Wray S 2012 Diabetes is associated with impairment of uterine contractility and high caesarean section rate. Diabetologia 55 489-498. (https://doi. org/10.1007/s00125-011-2371-6)

Andersen MR, Uldbjerg N, Stender S, Sandager P \& Aalkjaer C 2011 Maternal smoking and impaired endothelium-dependent nitric oxidemediated relaxation of uterine small arteries in vitro. American Journal of Obstetrics and Gynecology 204 177.e171-177.e177. (https://doi. org/10.1016/j.ajog.2010.09.006)

Arrowsmith S \& Wray S 2014 Oxytocin: its mechanism of action and receptor signalling in the myometrium. Journal of Neuroendocrinology 26 356-369. (https://doi.org/10.1111/jne.12154)

Arrowsmith S, Robinson H, Noble K \& Wray S 2012 What do we know about what happens to myometrial function as women age? Journal of Muscle Research and Cell Motility 33 209-217. (https://doi.org/10.1007/ s10974-012-9300-2)

Austin C \& Wray S 1994 A quantitative study of the relation between intracellular $\mathrm{pH}$ and force in rat mesenteric vascular smooth muscle. Pflugers Archiv 427 270-276. (https://doi.org/10.1007/BF00374534)

Austin C \& Wray S 1995 The effects of extracellular pH and calcium change on force and intracellular calcium in rat vascular smooth muscle. Journal of Physiology 488 281-291. (https://doi.org/10.1113/ jphysiol.1995.sp020966) 
Austin C \& Wray S 2000 Interactions between $\mathrm{Ca}^{2+}$ and $\mathrm{H}^{+}$and functional consequences in vascular smooth muscle. Circulation Research 86 355-363. (https://doi.org/10.1161/01.res.86.3.355)

Badran M, Abuyassin B, Ayas N \& Laher I 2019 Intermittent hypoxia impairs uterine artery function in pregnant mice. Journal of Physiology 597 2639-2650. (https://doi.org/10.1113/JP277775)

Bliss MR 1998 Hyperaemia. Journal of Tissue Viability 8 4-13. (https://doi. org/10.1016/s0965-206x(98)80028-4)

Borell U, Fernstroem I, Ohlson L \& Wiqvist N 1964 Effect of uterine contractions on the human uteroplacental blood circulation: an arteriographic study. American Journal of Obstetrics and Gynecology 89 881-890. (https://doi.org/10.1016/0002-9378(64)90057-2)

Boscardin E, Alijevic O, Hummler E, Frateschi S \& Kellenberger S 2016 The function and regulation of acid-sensing ion channels (ASICs) and the epithelial $\mathrm{Na}(+)$ channel $(\mathrm{ENaC})$ : IUPHAR review 19. British Journal of Pharmacology 173 2671-2701. (https://doi.org/10.1111/bph.13533)

Brar HS, Platt LD, DeVore GR, Horenstein J \& Medearis AL 1988 Qualitative assessment of maternal uterine and fetal umbilical artery blood flow and resistance in laboring patients by Doppler velocimetry. American Journal of Obstetrics and Gynecology 158 952-956. (https:// doi.org/10.1016/0002-9378(88)90100-7)

Brennan DJ, McGee SF, Rexhepaj E, O'Connor DP, Robson M \& O'Herlihy C 2011 Identification of a myometrial molecular profile for dystocic labor. BMC Pregnancy and Childbirth 11 74. (https://doi. org/10.1186/1471-2393-11-74)

Brooks GA 2020 Lactate as a fulcrum of metabolism. Redox Biology 35 101454. (https://doi.org/10.1016/j.redox.2020.101454)

Brotanek V, Hendricks CH \& Yoshida T 1969 Changes in uterine blood flow during uterine contractions. American Journal of Obstetrics and Gynecology 103 1108-1116. (https://doi.org/10.1016/00029378(69)90515-8)

Bugg GJ, Riley MJ, Johnston TA, Baker PN \& Taggart MJ 2006 Hypoxic inhibition of human myometrial contractions in vitro: implications for the regulation of parturition. European Journal of Clinical Investigation 36 133-140. (https://doi.org/10.1111/j.1365-2362.2006.01600.x)

Bullock AJ, Duquette RA, Buttell N \& Wray S 1998 Developmental changes in intracellular $\mathrm{pH}$ buffering power in smooth muscle. Pflugers Archiv 435 575-577. (https://doi.org/10.1007/s004240050555)

Burdyga T, Wray S \& Noble K 2007 In situ calcium signaling: no calcium sparks detected in rat myometrium. Annals of the New York Academy of Sciences 1101 85-96. (https://doi.org/10.1196/annals.1389.002)

Campbell JD \& Paul RJ 1992 The nature of fuel provision for the $\mathrm{Na}^{+}, \mathrm{K}^{+}$ATPase in porcine vascular smooth muscle. Journal of Physiology 447 67-82. (https://doi.org/10.1113/jphysiol.1992.sp018991)

Carlson NS, Hernandez TL \& Hurt KJ 2015 Parturition dysfunction in obesity: time to target the pathobiology. Reproductive Biology and Endocrinology 13 135. (https://doi.org/10.1186/s12958-015-0129-6)

Chaemsaithong P, Madan I, Romero R, Than NG, Tarca AL, Draghici S, Bhatti G, Yeo L, Mazor M, Kim CJ et al. 2013 Characterization of the myometrial transcriptome in women with an arrest of dilatation during labor. Journal of Perinatal Medicine 41 665-681. (https://doi. org/10.1515/jpm-2013-0086)

Chirayath HH, Wareing M, Taggart MJ \& Baker PN 2010 Endothelial dysfunction in myometrial arteries of women with gestational diabetes. Diabetes Research and Clinical Practice 89 134-140. (https://doi. org/10.1016/j.diabres.2010.03.022)

Cindrova-Davies T, Yung HW, Johns J, Spasic-Boskovic O, Korolchuk S, Jauniaux E, Burton GJ \& Charnock-Jones DS 2007 Oxidative stress, gene expression, and protein changes induced in the human placenta during labor. American Journal of Pathology 171 1168-1179. (https:// doi.org/10.2353/ajpath.2007.070528)

Corcoran D, Young R, Cialdella P, McCartney P, Bajrangee A, Hennigan B, Collison D, Carrick D, Shaukat A, Good R et al. 2018 The effects of remote ischaemic preconditioning on coronary artery function in patients with stable coronary artery disease. International Journal of Cardiology 252 24-30. (https://doi.org/10.1016/j.ijcard.2017.10.082)

Crichton CA, Taggart MJ, Wray S \& Smith GL 1993 Effects of pH and inorganic phosphate on force production in alpha-toxin-permeabilized isolated rat uterine smooth muscle. Journal of Physiology 465 629-645. (https://doi.org/10.1113/jphysiol.1993.sp019697)

Dawson MJ \& Wray S 1985 The effects of pregnancy and parturition on phosphorus metabolites in rat uterus studied by ${ }^{31} \mathrm{P}$ nuclear magnetic resonance. Journal of Physiology 368 19-31. (https://doi.org/10.1113/ jphysiol.1985.sp015844)

Dorup I, Skajaa K \& Sorensen KE 1999 Normal pregnancy is associated with enhanced endothelium-dependent flow-mediated vasodilation. American Journal of Physiology 276 H821-H825. (https://doi. org/10.1152/ajpheart.1999.276.3.H821)

Draeger A, Wray S \& Babiychuk EB 2005 Domain architecture of the smooth-muscle plasma membrane: regulation by annexins. Biochemical Journal 387 309-314. (https://doi.org/10.1042/BJ20041363)

Duprat F, Lesage F, Fink M, Reyes R, Heurteaux C \& Lazdunski M 1997 TASK, a human background $\mathrm{K}+$ channel to sense external $\mathrm{pH}$ variations near physiological pH. EMBO Journal 16 5464-5471. (https://doi. org/10.1093/emboj/16.17.5464)

Eckman DM, Gupta R, Rosenfeld CR, Morgan TM, Charles SM, Mertz H \& Moore LG 2012 Pregnancy increases myometrial artery myogenic tone via NOS- or COX-independent mechanisms. American Journal of Physiology: Regulatory, Integrative and Comparative Physiology 303 R368-R375. (https://doi.org/10.1152/ajpregu.00490.2011)

Eikens E \& Wilcken DE 1973 Myocardial reactive hyperemia and coronary vascular reactivity in the dog. Circulation Research 33 267-274. (https:// doi.org/10.1161/01.res.33.3.267)

Farrer-Brown G, Beilby JO \& Tarbit MH 1970 The blood supply of the uterus. 1. Arterial vasculature. Journal of Obstetrics and Gynaecology of the British Commonwealth 77 673-681. (https://doi. org/10.1111/j.1471-0528.1970.tb03592.x)

Fleet IR \& Heap RB 1982 Uterine blood flow, myometrial activity and their response to adenosine during the peri-implantation period in sheep. Journal of Reproduction and Fertility 65 195-205. (https://doi. org/10.1530/jrf.0.0650195)

Fleischhacker E, Esenabhalu VE, Spitaler M, Holzmann S, Skrabal F, Koidl B, Kostner GM \& Graier WF 1999 Human diabetes is associated with hyperreactivity of vascular smooth muscle cells due to altered subcellular $\mathrm{Ca}^{2+}$ distribution. Diabetes 48 1323-1330. (https://doi. org/10.2337/diabetes.48.6.1323)

Galley HF \& Webster NR 2004 Physiology of the endothelium. British Journal of Anaesthesia 93 105-113. (https://doi.org/10.1093/bja/ aeh163)

Gebremedhin D, Bonnet P, Greene AS, England SK, Rusch NJ, Lombard JH \& Harder DR 1994 Hypoxia increases the activity of $\mathrm{Ca}^{2+}$-sensitive $\mathrm{K}^{+}$ channels in cat cerebral arterial muscle cell membranes. Pflugers Archiv 428 621-630. (https://doi.org/10.1007/BF00374586)

Gourdin MJ, Bree B \& De Kock M 2009 The impact of ischaemiareperfusion on the blood vessel. European Journal of Anaesthesiology $\mathbf{2 6}$ 537-547. (https://doi.org/10.1097/EJA.0b013e328324b7c2)

Greiss Jr FC 1965 Effect of labor on uterine blood flow. Observations on gravid ewes. American Journal of Obstetrics and Gynecology 93 917-923. (https://doi.org/10.1016/0002-9378(65)90150-x)

Guibert C, Flemming R \& Beech DJ 2002 Prevention of a hypoxic $\mathrm{Ca}^{2+} \mathrm{i}$. British Journal of Pharmacology 135 927-934. (https://doi.org/10.1038/ sj.bjp.0704547)

Hanley JA, Weeks A \& Wray S 2015 Physiological increases in lactate inhibit intracellular calcium transients, acidify myocytes and decrease force in term pregnant rat myometrium. Journal of Physiology 593 4603-4614. (https://doi.org/10.1113/JP270631)

Harrison N, Larcombe-McDouall JB, Earley L \& Wray S 1994 An in vivo study of the effects of ischaemia on uterine contraction, intracellular $\mathrm{pH}$ and metabolites in the rat. Journal of Physiology 476 349-354. (https:// doi.org/10.1113/jphysiol.1994.sp020136)

Harrison N, Larcombe-McDouall JB \& Wray S 1995 A ${ }^{31} P$ NMR investigation into the effects of repeated vascular occlusion on uterine metabolites, intracellular $\mathrm{pH}$ and force, in vivo. NMR in Biomedicine 8 28-32. (https://doi.org/10.1002/nbm.1940080107)

Hayward CE, Cowley EJ, Mills TA, Sibley CP \& Wareing M 2014 Maternal obesity impairs specific regulatory pathways in human myometrial arteries. Biology of Reproduction 90 65. (https://doi.org/10.1095/ biolreprod.113.112623)

Heaton RC, Wray S \& Eisner DA 1993 Effects of metabolic inhibition and changes of intracellular $\mathrm{pH}$ on potassium permeability and contraction of rat uterus. Journal of Physiology 465 43-56. (https://doi.org/10.1113/ jphysiol.1993.sp019665)

Hedegaard ER, Nielsen BD, Kun A, Hughes AD, Kroigaard C, Mogensen S, Matchkov VV, Frobert O \& Simonsen U $2014 \quad K_{V} 7$ channels are 
involved in hypoxia-induced vasodilatation of porcine coronary arteries. British Journal of Pharmacology 171 69-82. (https://doi.org/10.1111/ bph.12424)

Herrera GM \& Walker BR 1998 Involvement of L-type calcium channels in hypoxic relaxation of vascular smooth muscle. Journal of Vascular Research 35 265-273. (https://doi.org/10.1159/000025593)

Hong SH, Sung R, Kim YC, Suzuki H, Choi W, Park YJ, Ji IW, Kim CH, Myung SC, Lee MY et al. 2013 Mechanism of relaxation via TASK2 channels in uterine circular muscle of mouse. Korean Journal of Physiology and Pharmacology 17 359-365. (https://doi.org/10.4196/ kjpp.2013.17.4.359)

Howard RB, Hosokawa T \& Maguire MH 1987 Hypoxia-induced fetoplacental vasoconstriction in perfused human placental cotyledons. American Journal of Obstetrics and Gynecology 157 1261-1266. (https://doi.org/10.1016/s0002-9378(87)80307-1)

Hu XQ, Xiao D, Zhu R, Huang X, Yang S, Wilson S \& Zhang L 2011 Pregnancy upregulates large-conductance $\mathrm{Ca}^{2+}$-activated $\mathrm{K}^{+}$channel activity and attenuates myogenic tone in uterine arteries. Hypertension $\mathbf{5 8}$ 1132-1139.(https://doi.org/10.1161/HYPERTENSIONAHA.111.179952)

Hu XQ, Xiao D, Zhu R, Huang X, Yang S, Wilson SM \& Zhang L 2012 Chronic hypoxia suppresses pregnancy-induced upregulation of large-conductance $\mathrm{Ca}^{2+}$-activated $\mathrm{K}^{+}$channel activity in uterine arteries. Hypertension $60 \quad 214-222$ (https://doi.org/10.1161/ HYPERTENSIONAHA.112.196097)

Hu XQ, Song R, Romero M, Dasgupta C, Huang X, Holguin MA, Williams V, Xiao D, Wilson SM \& Zhang L 2019 Pregnancy increases $\mathrm{Ca}^{2+}$ sparks/ spontaneous transient outward currents and reduces uterine arterial myogenic tone. Hypertension 73 691-702. (https://doi.org/10.1161/ HYPERTENSIONAHA.118.12484)

Iorizzo L, Klausen TW, Wiberg-Itzel E, Ovin F \& Wiberg N 2019 Use of lactate Pro(TM)2 for measurement of fetal scalp blood lactate during labor - proposing new cutoffs for normality, preacidemia and acidemia: a cross-sectional study. Journal of Maternal-Fetal and Neonatal Medicine 32 1762-1768. (https://doi.org/10.1080/14767058.2017.1416603)

Ireland Z, Castillo-Melendez M, Dickinson H, Snow R \& Walker DW 2011 A maternal diet supplemented with creatine from mid-pregnancy protects the newborn spiny mouse brain from birth hypoxia. Neuroscience 194 372-379. (https://doi.org/10.1016/j.neuroscience.2011.05.012)

Jaggar, Wellman, Heppner, Porter, Perez, Gollasch, Kleppisch, Rubart, Stevenson, Lederer et al. $1998 \mathrm{Ca}^{2+}$ channels, ryanodine receptors and $\mathrm{Ca}^{2+}$-activated $\mathrm{K}^{+}$channels: a functional unit for regulating arterial tone. Acta Physiologica Scandinavica 164 577-587. (https://doi.org/10.1046/ j.1365-201x.1998.00462.x)

Jones K, Shmygol A, Kupittayanant S \& Wray S 2004 Electrophysiological characterization and functional importance of calcium-activated chloride channel in rat uterine myocytes. Pflugers Archiv 448 36-43. (https://doi.org/10.1007/s00424-003-1224-7)

Jones NW, Raine-Fenning NJ, Jayaprakasan K, Mousa HA, Taggart MJ \& Bugg GJ 2009 Changes in myometrial 'perfusion' during normal labor as visualized by three-dimensional power Doppler angiography. Ultrasound in Obstetrics and Gynecology 33 307-312. (https://doi. org/10.1002/uog.6303)

Kazmierczak M, Zhang X, Chen B, Mulkey DK, Shi Y, Wagner PG, PivaroffWard K, Sassic JK, Bayliss DA \& Jegla T 2013 External pH modulates EAG superfamily $\mathrm{K}^{+}$channels through EAG-specific acidic residues in the voltage sensor. Journal of General Physiology 141 721-735. (https:// doi.org/10.1085/jgp.201210938)

Kirby LS, Kirby MA, Warren JW, Tran LT \& Yellon SM 2005 Increased innervation and ripening of the prepartum murine cervix. Journal of the Society for Gynecologic Investigation 12 578-585. (https://doi. org/10.1016/j.jsgi.2005.08.006)

Kyeong KS, Hong SH, Kim YC, Cho W, Myung SC, Lee MY, You RY, Kim CH, Kwon SY, Suzuki H et al. 2016 Myometrial relaxation of mice via expression of two pore domain acid sensitive $\mathrm{K}^{+}$(TASK-2) channels. Korean Journal of Physiology and Pharmacology 20 547-556. (https:// doi.org/10.4196/kjpp.2016.20.5.547)

Larcombe-McDouall JB, Harrison N \& Wray S 1998 The in vivo relationship between blood flow, contractions, $\mathrm{pH}$ and metabolites in the rat uterus. Pflugers Archiv 435 810-817. (https://doi.org/10.1007/ s004240050588)

Larcombe-McDouall J, Buttell N, Harrison N \& Wray S 1999 In vivo pH and metabolite changes during a single contraction in rat uterine smooth muscle. Journal of Physiology 518 783-790. (https://doi.org/10.1111/ j.1469-7793.1999.0783p.x)

Little PJ, Neylon CB, Farrelly CA, Weissberg PL, Cragoe Jr EJ \& Bobik A 1995 Intracellular $\mathrm{pH}$ in vascular smooth muscle: regulation by sodiumhydrogen exchange and multiple sodium dependent $\mathrm{HCO}_{3}{ }^{-}$mechanisms. Cardiovascular Research 29 239-246. (https://doi.org/10.1016/00086363(96)88576-2)

Loboda A, Jozkowicz A \& Dulak J 2010 HIF-1 and HIF-2 transcription factors - similar but not identical. Molecules and Cells 29 435-442. (https://doi.org/10.1007/s10059-010-0067-2)

Longo M, Jain V, Vedernikov YP, Hankins GD, Garfield RE \& Saade GR 2003 Effects of L-type $\mathrm{Ca}^{2+}$-channel blockade, $\mathrm{K}^{+}$ATP-channel opening and nitric oxide on human uterine contractility in relation to gestational age and labour. Molecular Human Reproduction 9 159-164. (https://doi. org/10.1093/molehr/gag023)

Lovgren B \& Hellstrand P 1985 Graded effects of oxygen and respiratory inhibitors on cell metabolism and spontaneous contractions in smooth muscle of the rat portal vein. Acta Physiologica Scandinavica 123 485-495. (https://doi.org/10.1111/j.1748-1716.1985.tb07614.x)

Lutton EJ, Lammers WJEP, James S, van den Berg HA \& Blanks AM 2018 Identification of uterine pacemaker regions at the myometrial-placental interface in the rat. Journal of Physiology 596 2841-2852. (https://doi. org/10.1113/JP275688)

Madaan A, Nadeau-Vallée M, Rivera JC, Obari D, Hou X, Sierra EM, Girard S, Olson DM \& Chemtob S 2017 Lactate produced during labor modulates uterine inflammation via GPR81 (HCA(1)). American Journal of Obstetrics and Gynecology 216 60.e61-60.e17. (https://doi. org/10.1016/j.ajog.2016.09.072)

Maigaard S, Forman A \& Andersson KE 1986 Differential effects of angiotensin, vasopressin and oxytocin on various smooth muscle tissues within the human uteroplacental unit. Acta Physiologica Scandinavica 128 23-31. (https://doi.org/10.1111/j.1748-1716.1986.tb07945.x)

Makkonen M, Puhakainen E, Hänninen O \& Castrén O 1982 Lactate dehydrogenase isoenzymes in human myometrium during pregnancy and labor. Acta Obstetricia et Gynecologica Scandinavica 61 35-37. (https://doi.org/10.3109/00016348209156948)

Messere A, Turturici M, Millo G \& Roatta S 2017 Repetitive muscle compression reduces vascular mechano-sensitivity and the hyperemic response to muscle contraction. Journal of Physiology and Pharmacology 68 427-437.

Milwidsky A \& Gutman A 1983 Glycogen metabolism of normal human myometrium and leiomyoma - possible hormonal control. Gynecologic and Obstetric Investigation 15 147-152. (https://doi. org/10.1159/000299405)

Mittal P, Romero R, Tarca AL, Draghici S, Nhan-Chang CL, Chaiworapongsa T, Hotra J, Gomez R, Kusanovic JP, Lee DC et al. 2011 A molecular signature of an arrest of descent in human parturition. American Journal of Obstetrics and Gynecology 204 177.e15-177.e33. (https://doi.org/10.1016/j.ajog.2010.09.025)

Monir-Bishty E, Pierce SJ, Kupittayanant S, Shmygol A \& Wray S 2003 The effects of metabolic inhibition on intracellular calcium and contractility of human myometrium. BJOG 110 1050-1056. (https://doi.org/10.1111/ j.1471-0528.2003.03103.x)

Neilson JP, Lavender T, Quenby S \& Wray S 2003 Obstructed labour. British Medical Bulletin 67 191-204. (https://doi.org/10.1093/bmb/ldg018)

Nelson SH, Steinsland OS, Wang Y, Yallampalli C, Dong YL \& Sanchez JM 2000 Increased nitric oxide synthase activity and expression in the human uterine artery during pregnancy. Circulation Research 87 406-411. (https://doi.org/10.1161/01.res.87.5.406)

Noble K, Zhang J \& Wray S 2006 Lipid rafts, the sarcoplasmic reticulum and uterine calcium signalling: an integrated approach. Journal of Physiology $\mathbf{5 7 0}$ 29-35. (https://doi.org/10.1113/ jphysiol.2005.098475)

Noble D, Borysova L, Wray S \& Burdyga T 2014 Store-operated Ca ${ }^{2+}$ entry and depolarization explain the anomalous behaviour of myometrial SR: effects of SERCA inhibition on electrical activity, $\mathrm{Ca}^{2+}$ and force. Cell Calcium 56 188-194. (https://doi.org/10.1016/j.ceca.2014.07.003)

Osol G \& Mandala M 2009 Maternal uterine vascular remodeling during pregnancy. Physiology 24 58-71. (https://doi.org/10.1152/ physiol.00033.2008)

Page KL, Celia G, Leddy G, Taatjes DJ \& Osol G 2002 Structural remodeling of rat uterine veins in pregnancy. American Journal of 
Obstetrics and Gynecology 187 1647-1652. (https://doi.org/10.1067/ mob.2002.127599)

Pearce WJ, Ashwal S, Long DM \& Cuevas J 1992 Hypoxia inhibits calcium influx in rabbit basilar and carotid arteries. American Journal of Physiology 262 H106-H113. (https://doi.org/10.1152/ajpheart.1992.262.1.H106)

Peebles DM, Spencer JA, Edwards AD, Wyatt JS, Reynolds EO, Cope M \& Delpy DT 1994 Relation between frequency of uterine contractions and human fetal cerebral oxygen saturation studied during labour by near infrared spectroscopy. British Journal of Obstetrics and Gynaecology 101 44-48. (https://doi.org/10.1111/j.1471-0528.1994.tb13008.x)

Pierce SJ, Kupittayanant S, Shmygol T \& Wray S 2003 The effects of pH change on $\mathrm{Ca}(++)$ signaling and force in pregnant human myometrium. American Journal of Obstetrics and Gynecology 188 1031-1038. (https://doi.org/10.1067/mob.2003.229)

Pijnenborg R, Vercruysse L \& Hanssens M 2006 The uterine spiral arteries in human pregnancy: facts and controversies. Placenta 27 939-958. (https://doi.org/10.1016/j.placenta.2005.12.006)

Piper I, Minshall E, Downing SJ, Hollingsworth M \& Sadraei H 1990 Effects of several potassium channel openers and glibenclamide on the uterus of the rat. British Journal of Pharmacology 101 901-907. (https://doi. org/10.1111/j.1476-5381.1990.tb14178.x)

Prendergast C 2020 Maternal phenotype: how does age, obesity and diabetes affect myometrial function? Current Opinion in Physiology 13 108-116. (https://doi.org/10.1016/j.cophys.2019.10.016)

Prendergast C \& Wray S 2019 Human myometrial artery function and endothelial cell calcium signalling are reduced by obesity: can this contribute to poor labour outcomes? Acta Physiologica 227 e13341. (https://doi.org/10.1111/apha.13341)

Quenby S, Pierce SJ, Brigham S \& Wray S 2004 Dysfunctional labor and myometrial lactic acidosis. Obstetrics and Gynecology 103 718-723. (https://doi.org/10.1097/01.AOG.0000118306.82556.43)

Rosenfeld CR, Roy T, DeSpain K \& Cox BE 2005 Large-conductance $\mathrm{Ca}^{2+}$ dependent $\mathrm{K}^{+}$channels regulate basal uteroplacental blood flow in ovine pregnancy. Journal of the Society for Gynecologic Investigation 12 402-408. (https://doi.org/10.1016/j.jsgi.2005.04.009)

Sawada K, Morishige K, Hashimoto K, Tasaka K, Kurachi H, Murata Y \& Kurachi Y 2005 Gestational change of $\mathrm{K}^{+}$channel opener effect is correlated with the expression of uterine KATP channel subunits. European Journal of Obstetrics, Gynecology, and Reproductive Biology 122 49-56. (https://doi.org/10.1016/j.ejogrb.2004.11.026)

Shephard RJ 2002 Cytokine responses to physical activity, with particular reference to IL-6: sources, actions, and clinical implications. Critical Reviews in Immunology 22 165-182. (https://doi.org/10.1615/ critrevimmunol.v22.i3.10)

Shimoda LA \& Polak J 2011 Hypoxia. 4. Hypoxia and ion channel function. American Journal of Physiology: Cell Physiology 300 C951C967. (https://doi.org/10.1152/ajpcell.00512.2010)

Shmigol AV, Eisner DA \& Wray S 1998 Properties of voltage-activated $\left[\mathrm{Ca}^{2+}\right]_{\mathrm{i}}$ transients in single smooth muscle cells isolated from pregnant rat uterus. Journal of Physiology 511 803-811. (https://doi.org/10.1111/ j.1469-7793.1998.803bg.x)

Shmigol AV, Eisner DA \&Wray S 1999 The role of the sarcoplasmic reticulum as a Ca2 + sink in rat uterine smooth muscle cells. Journal of Physiology 520 153-163. (https://doi.org/10.1111/j.1469-7793.1999.00153.x)

Shmygol A, Noble K \& Wray S 2007 Depletion of membrane cholesterol eliminates the $\mathrm{Ca} 2+$-activated component of outward potassium current and decreases membrane capacitance in rat uterine myocytes. Journal of Physiology $\mathbf{5 8 1}$ 445-456. (https://doi.org/10.1113/ jphysiol.2007.129452)

Smani T, Hernandez A, Urena J, Castellano AG, Franco-Obregon A, Ordonez A \& Lopez-Barneo J 2002 Reduction of $\mathrm{Ca}^{2+}$ channel activity by hypoxia in human and porcine coronary myocytes. Cardiovascular Research 53 97-104. (https://doi.org/10.1016/s0008-6363(01)00422-9)

Smith GL, Austin C, Crichton C \& Wray S 1998 A review of the actions and control of intracellular $\mathrm{pH}$ in vascular smooth muscle. Cardiovascular Research 38 316-331. (https://doi.org/10.1016/s00086363(98)00020-0)

Steingrímsdóttir T, Ronquist G \& Ulmsten U 1993 Energy economy in the pregnant human uterus at term: studies on arteriovenous differences in metabolites of carbohydrate, fat and nucleotides. European Journal of Obstetrics, Gynecology, and Reproductive Biology 51 209-215. (https:// doi.org/10.1016/0028-2243(93)90037-d)
Steingrímsdóttir T, Ericsson A, Franck A, Waldenström A, Ulmsten U \& Ronquist G 1997 Human uterine smooth muscle exhibits a very low phosphocreatine/ATP ratio as assessed by in vitro and in vivo measurements. European Journal of Clinical Investigation 27 743-749. (https://doi.org/10.1046/j.1365-2362.1997.1810726.x)

Taggart M \& Wray S 1993 Simultaneous measurement of intracellular $\mathrm{pH}$ and contraction in uterine smooth muscle. Pflugers Archiv 423 527-529. (https://doi.org/10.1007/BF00374951)

Taggart MJ \& Wray S 1998 Hypoxia and smooth muscle function: key regulatory events during metabolic stress. Journal of Physiology $\mathbf{5 0 9}$ 315-325. (https://doi.org/10.1111/j.1469-7793.1998.315bn.x)

Taggart MJ, Menice CB, Morgan KG \& Wray S 1997 Effect of metabolic inhibition on intracellular $\mathrm{Ca} 2+$, phosphorylation of myosin regulatory light chain and force in rat smooth muscle. Journal of Physiology 499 485-496. (https://doi.org/10.1113/jphysiol.1997.sp021943)

Teramoto N 2006 Physiological roles of ATP-sensitive $\mathrm{K}^{+}$channels in smooth muscle. Journal of Physiology 572 617-624. (https://doi. org/10.1113/jphysiol.2006.105973)

Turner JM, Mitchell MD \& Kumar SS 2020 The physiology of intrapartum fetal compromise at term. American Journal of Obstetrics and Gynecology 222 17-26. (https://doi.org/10.1016/j.ajog.2019.07.032)

Turturici M \& Roatta S 2013 Inactivation of mechano-sensitive dilatation upon repetitive mechanical stimulation of the musculo-vascular network in the rabbit. Journal of Physiology and Pharmacology 64 299-308.

Vanhoutte PM, Shimokawa H, Feletou M \& Tang EH 2017 Endothelial dysfunction and vascular disease - a 30th anniversary update. Acta Physiologica 219 22-96. (https://doi.org/10.1111/apha.12646)

Wiberg-Itzel E, Pettersson H, Cnattingius S \& Nordstrom L 2009 Prediction of time to spontaneous onset of labour with lactate concentration in vaginal fluid in women with suspected preterm prelabour rupture of the membranes. BJOG 116 62-66. (https://doi.org/10.1111/j.14710528.2008.02017.x)

Wiberg-Itzel E, Pettersson H, Andolf E, Hansson A, Winbladh B \& Akerud H 2010 Lactate concentration in amniotic fluid: a good predictor of labor outcome. European Journal of Obstetrics, Gynecology, and Reproductive Biology 152 34-38. (https://doi.org/10.1016/j.ejogrb.2010.05.005)

Wiberg-Itzel E, Pembe AB, Wray S, Wihlbäck AC, Darj E, Hoesli I \& Åkerud H 2014 Level of lactate in amniotic fluid and its relation to the use of oxytocin and adverse neonatal outcome. Acta Obstetricia et Gynecologica Scandinavica 93 80-85. (https://doi.org/10.1111/ aogs.12261)

Wiberg-Itzel $E$, Pembe $A B$, Järnbert-Pettersson $H$, Norman $M$, Wihlbäck AC, Hoesli I, Todesco Bernasconi M, Azria E, Åkerud H \& Darj E 2016 Lactate in amniotic fluid: predictor of labor outcome in oxytocin-augmented primiparas' deliveries. PLOS ONE 11 e0161546. (https://doi.org/10.1371/journal.pone.0161546)

Wiberg-Itzel E, Wray S \& Akerud H 2018 A randomized controlled trial of a new treatment for labor dystocia. Journal of Maternal-Fetal and Neonatal Medicine 31 2237-2244. (https://doi.org/10.1080/14767058 .2017.1339268)

Wray S 1990 The effects of metabolic inhibition on uterine metabolism and intracellular $\mathrm{pH}$ in the rat. Journal of Physiology 423 411-423. (https:// doi.org/10.1113/jphysiol.1990.sp018030)

Wray S 2015 Insights from physiology into myometrial function and dysfunction. Experimental Physiology 100 1468-1476. (https://doi. org/10.1113/EP085131)

Wray S \& Arrowsmith S 2012 Uterine Smooth Muscle In Muscle: Fundamental Biology and Mechanisms of Disease, Volume 2 pp. 1207-1216 Elsevier Inc.. (https://doi.org/10.1016/b978-0-12-3815101.00090-9)

Wray S \& Prendergast C 2019 The myometrium: from excitation to contractions and labour. Advances in Experimental Medicine and Biology 1124 233-263. (https://doi.org/10.1007/978-981-13-5895-1_10)

Wynn RM 1967 Cellular Biology of the Uterus. New York: AppletonCentury-Crofts.

Xiao D, Hu XQ, Huang X, Zhou J, Wilson SM, Yang S \& Zhang L 2013 Chronic hypoxia during gestation enhances uterine arterial myogenic tone via heightened oxidative stress. PLOS ONE 8 e73731. (https://doi. org/10.1371/journal.pone.0073731)

Xiao D, Longo LD \& Zhang L 2010 Role of KATP and L-type Ca2+ channel activities in regulation of ovine uterine vascular contractility: effect of pregnancy and chronic hypoxia. American Journal of Obstetrics 
and Gynecology 203 596.e6-596.e12. (https://doi.org/10.1016/j. ajog.2010.07.038)

Xu C, You X, Gao L, Zhang L, Hu R, Hui N, Olson DM \& Ni X 2011 Expression of ATP-sensitive potassium channels in human pregnant myometrium. Reproductive Biology and Endocrinology 9 35. (https:// doi.org/10.1186/1477-7827-9-35)

Young RC 2016 Mechanotransduction mechanisms for coordinating uterine contractions in human labor. Reproduction 152 R51-R61. (https://doi. org/10.1530/REP-16-0156)

Zhang L \& Xiao D 1998 Effects of chronic hypoxia on $\mathrm{Ca}^{2+}$ mobilization and $\mathrm{Ca}^{2+}$ sensitivity of myofilaments in uterine arteries. American Journal of Physiology 274 H132-H138. (https://doi.org/10.1152/ ajpheart.1998.274.1.H132)
Zhang J, Bricker L, Wray S \& Quenby S 2007 Poor uterine contractility in obese women. BJOG 114 343-348. (https://doi.org/10.1111/j.14710528.2006.01233.x)

Received 18 June 2020

First decision 14 August 2020

Revised manuscript received 21 October 2020

Accepted 26 October 2020 